\title{
Mass spectrometry based evolved gas analysis system for thermal decomposition studies
}

\author{
S DASH, M KAMRUDDIN and A K TYAGI* \\ Materials Science Division, Indira Gandhi Centre for Atomic Research, Kalpakkam 603102 , \\ India \\ MS received 22 March 1997

\begin{abstract}
An experimental facility for evolved gas analysis by mass spectrometry (EGA-MS) has been built in-house and extensively used to study the temperature programmed decomposition (TPD) of a number of inorganic solids. Fractional extent of reaction $\alpha$ acquired from real time multiple ion detection trend analysis mass spectra of gases released from thermally impressed specimen has been used to obtain functional transform $f(\alpha)$ of non-isothermal solid state kinetic rate expressions. The corresponding model integral functions $g(\alpha)$ based on mechanisms like random nucleation, diffusion and interface motion have been used to establish kinetics control regimes for specific decomposition sequences. From $\ln \left[g(\alpha) / T^{2}\right]$ vs $1 / T$ plots Arrhenius parameters like activation energy and pre-exponential factor could be determined. Signature of the rate controlling mechanism governing the gas release behaviour was found in the crystallographic transformation brought about by the temperature programme. This paper describes the scope and capabilities of our EGA-MS facility with typical results on temperature programmed decomposition of $\mathrm{CuSO}_{4} \cdot 5 \mathrm{H}_{2} \mathrm{O}$ and $\mathrm{AlNH}_{4}\left(\mathrm{SO}_{4}\right)_{2} \cdot 12 \mathrm{H}_{2} \mathrm{O}$.
\end{abstract}

Keywords. Evolved gas analysis; temperature programmed decomposition; real time mass spectrometry; thermal analysis; non-isothermal kinetics.

\section{Introduction}

Various thermoanalytical techniques like thermogravimetry (TG), differential thermal analysis (DTA) and differential scanning calorimetry (DSC) have emerged as valuable tools to fingerprint kinetics and mechanism involved in wide range of solid state transformations (Dollimore 1992). These techniques record variational trend in mass and/or energy as key parameters to identify processes related to kinetics and energetics. However, while applied to the study of complex gas evolution processes from solids, these techniques have the limitations like non-specificity and poor resolution with respect to partial reactions occurring simultaneously as the measured quantity will be due to overall reaction. This applies to a large number of solid state reactions like gas-solid interactions, thermal decomposition and catalysis which accompany with release of a number of product gaseous species. In such cases, real time monitoring of product gases is capable of providing information on subtle reaction steps. Hence methods based on real time evolved gas analysis (EGA) is often found to be superior to conventional thermoanalytical techniques (Langer 1983). Having identified different stages, the process can be interrupted at desired levels and residues can be subjected to off-line analyses. This complementary information on product gases as well as reaction intermediates helps in predicting the reaction pathway and their mechanisms.

This approach, based on dynamic on-line monitoring of process yield gas, is applicable to the study of solid state kinetics of a large number of heterogeneous

\footnotetext{
*Author for correspondence
} 
interfacial processes involving gas-solid interactions (Szekely et al 1976). Technologically relevant processes like adsorption (Benham and Ross 1989), catalysis (Barnes et al 1994; Dossi et al 1994), decomposition (Pysiak and Pacewska 1980), calcination, roasting, smelting, plasma processing of materials (Gordiets et al 1996), high temperature gas-metal interactions (Jaenicke-Rößler et al 1994) and gas loading by porous solids (Davis 1991) etc where atleast one of the reaction products is a gas can be studied by this approach (Sestak et al 1973). A previous knowledge of single particle kinetics and total evolved gas quantities are absolutely essential for optimizing the design parameters for process control as well as down stream gas management equipment. As these processes involve release of noxious gases (Stucker 1991) like $\mathrm{NH}_{3}, \mathrm{NO}_{x}, \mathrm{SO}_{x}$, $\mathrm{CO}, \mathrm{CO}_{2}$ and hydrocarbons, quantitative study of these release behaviours will also help in improvising the design of pollution control equipment (Bell et al 1995).

Thermogravimetry (TG), in conjunction with many conventional gas analytical instruments like gas chromatography (Lorinci et al 1995) and infra-red spectrometry (Mullens et al 1992; Eroglu and Guven 1996) have been the widely used techniques for EGA studies relevant to gas-solid interactions (Kaisersberger 1979). However, mass spectrometry based EGA holds a decisive edge over other conventional techniques (Price et al 1980, 1985; Gallagher 1982; Barnes 1987) in terms of specificity, high sensitivity, simultaneous identification of several unknown species and fast response. The advent of specially built and easily process adaptable quadrupole mass spectrometers have facilitated their wide spread usage.

In order to cater to above requirements, a mass spectrometry based evolved gas analyser (EGA-MS) has been designed and built in our laboratory (Kamruddin et al 1995). The system was calibrated by carrying out the well studied thermal decomposition of $\mathrm{CaCO}_{3}$ (Jisheng Wang and Brian McEnaney 1991). This system was used to study the temperature programmed decomposition of a wide variety of inorganic solids. The samples studied include simple salts like $\mathrm{CuSO}_{4} \cdot 5 \mathrm{H}_{2} \mathrm{O}, \mathrm{Pb}\left(\mathrm{NO}_{3}\right)_{2}$, double salts like $\mathrm{AlNH}_{4}\left(\mathrm{SO}_{4}\right)_{2} \cdot 12 \mathrm{H}_{2} \mathrm{O}$, $\mathrm{KAl}\left(\mathrm{SO}_{4}\right)_{2} \cdot 12 \mathrm{H}_{2} \mathrm{O}$, materials relevant to nuclear industry like $\mathrm{UO}_{2}\left(\mathrm{NO}_{3}\right)_{2} \cdot 6 \mathrm{H}_{2} \mathrm{O}$, $\mathrm{Th}\left(\mathrm{NO}_{3}\right)_{4} \cdot 5 \mathrm{H}_{2} \mathrm{O}$ (Dash et al 1997), Th( $\left(\mathrm{C}_{2} \mathrm{O}_{4}\right)_{2} \cdot 6 \mathrm{H}_{2} \mathrm{O}$, complex salts of cobalt ethylenediamene (Ajikumar et al 1996) and polymers. The evolved gas analysis mass spectrometry data obtained in temperature domain has been utilized for constructing decomposition profiles. The fractional reaction parameter $(\alpha)$ evaluated from above profiles has been used to assess various non-isothermal kinetic equation models through the integral model function $g(\alpha)$ approach (Brown et al 1980; Brown 1988; Koga et al 1993) and to arrive at reaction mechanism and kinetic parameters. Also the concomitant structural transformation in the condensed phase could be correlated with gas release behaviour by subjecting the residue to off-line analytical examination by powder X-ray diffractometry. In certain cases, these structure - property relations with respect to analysis of EGA-MS spectra could be established from the reported literature. This paper gives a brief description of the EGA-MS facility high-lighting its salient features and the results on temperature programmed decomposition of $\mathrm{CuSO}_{4} \cdot 5 \mathrm{H}_{2} \mathrm{O}$ and $\mathrm{AlNH}_{4}\left(\mathrm{SO}_{4}\right)_{2} \cdot 12 \mathrm{H}_{2} \mathrm{O}$ for bringing out the capability of the system.

\section{Experimental set-up}

Figure 1 gives the process and instrumentation diagram of our evolved gas analysis by mass spectrometry (EGA-MS) facility for studying the thermal stability of a wide range 


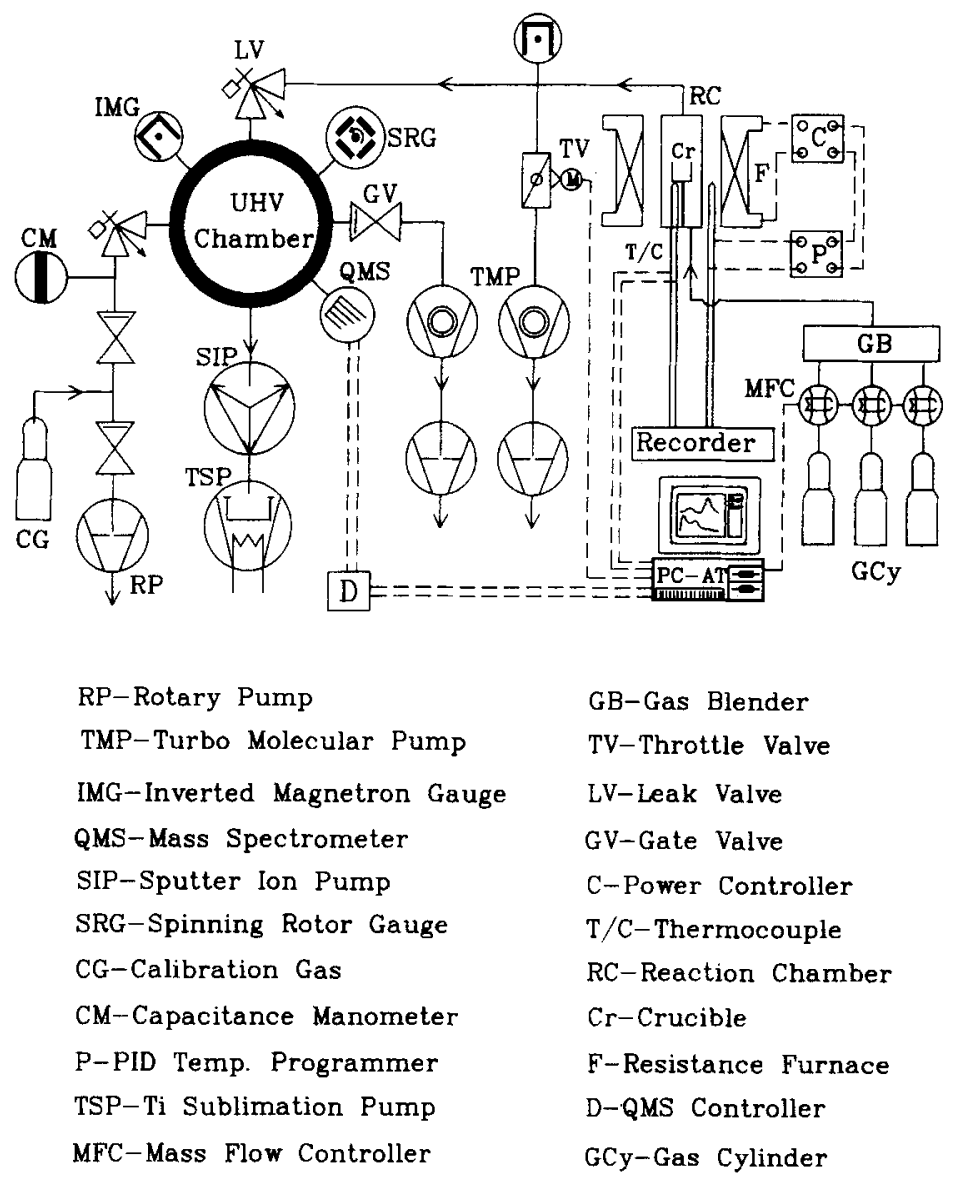

Figure 1. Process and instrumentation diagram of evolved gas analysis mass spectrometry (EGA-MS) facility.

of inorganic solids under high vacuum condition or in flowing gaseous stream (Kamruddin et al 1995). The high vacuum environment ensures integrity of evolved species by avoiding gas phase recombination and reverse reactions which may lead to incorrect interpretation. This experimental facility essentially consists of a high temperature high vacuum compatible quartz reaction chamber which is appended to an ultra high vacuum mass spectrometer chamber through a variable conductance molecular leak valve (Dash et al 1995). The high vacuum quartz reaction chamber is evacuable to a pressure of $1.0 \times 10^{-7}$ mbar by a turbomolecular pumping unit. The reaction chamber is provided with a gas delivery system consisting of four mass flow controllers (MFC) and gas blender so that active gas and an inert carrier gas or any other combination of gas mixture at required ratio can be prepared and made to flow past the specimen undergoing the temperature programme. The pressure of this gas stream can be pre-set and controlled by a computer controlled throttle valve working in conjunction with a capacitance manometer. These additions have enhanced the capability of the system to study gas-solid interactions of technical relevance under controlled dynamic atmosphere, pressure and temperature schedules. 
The bakeable all metal ultra high vacuum chamber is pumped by turbomolecular pump system, triode sputter ion pump and a titanium sublimation pump to a base pressure of $5 \times 10^{-11}$ mbar. Besides the quadrupole mass analyser (QMA), this chamber is equipped with other vacuum metrological hardware like inverted magnetron gauge (IMG), spinning rotor viscosity gauge (SRG) and calibration gas inlets. The molecular leak value provided at the calibration gas inlet can also be used for injecting unknown gas mixture for analysis. Hence the system has the capability to operate in three different modes, namely (i) temperature programmed decomposition, (ii) gas-solid interactions under controlled atmosphere and pressure and (iii) analysis of unknown gas mixtures.

A programmable autotune Eurotherm PID temperature controller with a thyristor controlled power supply enable the resistance furnace, which surrounds the quartz reaction chamber, to achieve a maximum temperature of $1400 \mathrm{~K}$ at typical ramp rates ranging between $2 \mathrm{~K} / \mathrm{min}$ and $15 \mathrm{~K} / \mathrm{min}$. There are two calibrated $\mathrm{K}$-type chromel/alumel thermocouples kept in contact with specimen holder. One is used to control and record the furnace temperature and the other is connected to $\mathrm{PC}$ through a thermocouple add-on card to read the sample temperature by the data acquisition software. A multipen strip chart recorder is also used to track temperature besides other process parameters. The temperature range of the system is being upgraded to $2000 \mathrm{~K}$ by incorporating a high temperature and low thermal mass furnace. Calibration of the EGA system is effected by bleeding in known quantities of gas through the molecular leak valve. There is also a provision for calibrating mass spectrometer against absolute pressure readings from the spinning rotor viscosity gauge.

Having separate reaction and measurement chambers has the following advantages. It has high detection limit due to very low background in the measurement chamber. There is no memory effect as the mass spectrometer chamber is not contaminated by the reaction environment and only a very small quantity of product gas is let in for analysis. It is easy to provide wide range of reaction conditions. Sample loading is easy and limitation in sample size and shape is less. However, in design stage adequate precaution is taken to avoid any time lag between gas release and detection by minimizing the dead volume and the gas path to measurement chamber is heated to avoid capillary condensation.

The quadrupole mass spectrometer is interfaced to a PC 486 through RS232C interface for real time data acquisition. The essential software for obtaining temperature programmed multiple ion detection on-line trend analysis mass spectra over a wide dynamic pressure regime has been developed by us (Saraswathy 1994). The software is designed to track ion intensities of up to eight different masses $(m / Z)$ and sample temperature quasi-simultaneously. The temperature dependent multi-channel trend analysis spectra are constructed by plotting ion intensities against sample temperature.

The $\mathrm{CuSO}_{4} \cdot 5 \mathrm{H}_{2} \mathrm{O}$ and $\mathrm{AlNH}_{4}\left(\mathrm{SO}_{4}\right)_{2} \cdot 12 \mathrm{H}_{2} \mathrm{O}$ used in this study are of $\mathrm{AR}$ grade which are used as such in the powder form without any further treatment. Typical sample weights of $100-200 \mathrm{mg}$ are taken in flat bottom alumina/boron nitride crucible for vacuum decomposition in the temperature range $300-1300 \mathrm{~K}$, at heating rates 2 to $14 \mathrm{~K} / \mathrm{min}$. In case of Alum, the decomposition runs were interrupted at different stages and the solid residue was subjected to off-line XRD analysis. 


\section{Principles of kinetic analysis}

The mathematical formalism to study reactivity through single particle kinetics is normally based on fractional reaction parameter ' $\alpha$ ' (Brown et al 1980). This is motivated by the need to use a suitable conversional transformation in the rate expression of solid state reactions yielding gaseous products upon decomposition. The rate of the reaction vary with both ' $\alpha$ ' and $T$. It can be given as

$$
\mathrm{d} \alpha / \mathrm{d} t=k(T) * f(\alpha)
$$

where $k(T)$ is temperature dependent specific rate constant and is expressed by the Arrhenius equation as

$$
k(T)=Z \exp (-E / R T),
$$

where $Z$ is pre-exponential factor and $E$ the activation energy barrier. In the case of linear temperature scheduling with constant heating rate $\beta(=\mathrm{d} T / \mathrm{d} t)$, the temperature $T$ at any time can be given as

$$
T=T_{0}+\beta t
$$

where $T_{0}$ is the initial temperature.

The second term in the rate expression ' $f(\alpha)$ ' is a function of the instantaneous phase composition of the system and generally represents the controlling mechanism. The functional transform $f(\alpha)$ expressible as analytical functions is crucially dependent on kinetic control mechanisms like random nucleation, diffusion and phase boundary interface motion(Brown 1988; Flynn 1988; Agrawal 1992; Koga et al 1993). A list of $f(\alpha)$ expression based on above formalisms is given in table 1. Having defined the $k(T)$ term now the task of the non-isothermal temperature programmed technique is to obtain analytical expression for $f(\alpha)$.

For a decomposition process, conducted under linear temperature programme, (1) can be written as

$$
\mathrm{d} \alpha / \mathrm{d} T=Z / \beta(\exp (-E / R T)) * f(\alpha),
$$

rearranging and integration within limits yields

$$
\int_{0}^{\alpha} \mathrm{d} \alpha / f(\alpha)=Z / \beta \int_{0}^{T} \exp (-E / R T) \mathrm{d} T,
$$

where left hand side can be written as ' $g(\alpha)$ ' which denotes integral model functions and the initial value $T_{0}$ is set to zero as $\alpha$ is zero up to temperature $T_{0}$. Substitution of $E / R T$ with ' $x$ ' converts the equation to

$$
g(x)=Z E / \beta R \int_{x}^{x}\left(e^{-x} / x^{2}\right) \mathrm{d} x=Z E / \beta R[P(x)],
$$

for $x>15$, the integral $P(x)$ is best solved by Schlomlich series expansion (Sestak et al 1973):

$$
\begin{aligned}
P(x)= & \left(e^{-x} / x(x+1)\right)[1-1 /(x+2)+1 /(x+2)(x+3) \\
& \left.+(-1)^{n} A_{n} /(x+2)(x+3)(x+4)+\cdots\right],
\end{aligned}
$$

where $A_{n}$ is a specific constant. 
Table 1. Non-isothermal, integral forms of kinetic expression for heterogeneous solid-state reactions.

Sl.

No. Rate determining mechanism

Symbol $f(\alpha)$

$g(\alpha)=\int_{0}^{\infty} \mathrm{d}(\alpha) / f(\alpha)$

1. Nucleation and growth models Random nucleation approach

(i) Mampel unimolecular law

(ii) Avrami-Erofeev nuclei growth:
(a) 2-dimensional growth
(b) 3-dimensional growth
(iii) Branching nuclei:
Prout Tompkins branching nuclei
A2 $2(1-\alpha)[-\ln (1-\alpha)]^{1 / 2} \quad[-\ln (1-\alpha)]^{1 / 2}$
A3 $3(1-\alpha)[-\ln (1-\alpha)]^{2 / 3} \quad[-\ln (1-\alpha)]^{1 / 3}$
A4 $\alpha(1-\alpha) \quad \ln [\alpha /(1-\alpha)]$

Al $\quad 1-\alpha$

$-\ln (1-\alpha)$

2. Decelerating rate equations based on diffusion

(i) Parabolic law 1-dimensional transport

D1 $\alpha^{-1} \quad \alpha^{2} / 2$

(ii) 2-dimensional diffusion

(iii) 3-dimensional diffusion

D2 $\quad[-\ln (1-\alpha)]^{-1}$

$(1-\alpha)[\ln (1-\alpha)]+\alpha$

(Jander)

(iv) 3-dimensional diffusion

(Ginstling-Brounshtein)

D3 $\quad(1-\alpha)^{1 / 3}\left[(1-\alpha)^{-1 / 3}-1\right]^{-1}$

$1 \cdot 5\left[1-(1-\alpha)^{1 / 3}\right]^{2}$

D4 $\left[(1-\alpha)^{-1 / 3}-1\right]^{-1} \quad 1 \cdot 5\left[1-2 \alpha / 3-(1-\alpha)^{2 / 3}\right]$

3. Phase boundary movement

(i) 1-dimensional (Zero order)

(ii) 2-dimensional (cylindrical symmetry)

R1 Constant $\alpha$

(iii) 3-dimensional (spherical symmetry)

R2 $(1-\alpha)^{1 / 2}$

$2\left[1-(1-\alpha)^{1 / 2}\right]$

R3 $\quad(1-\alpha)^{2 / 3}$

$3\left[1-(1-\alpha)^{1 / 3}\right]$

The first two significant terms of the series sum up as

$$
P(x)=(x-2) * e^{-x} * x^{-3} .
$$

Upon substitution, the expression for $g(\alpha)$ converts to

$$
g(\alpha)=\left(Z R T^{2} / \beta E\right)[1-2 R T / E] * \exp (-E / R T),
$$

the middle term inside square bracket drops off as $2 R T / E \ll 1$. Upon rearranging the terms and taking logarithms, (9) becomes

$$
\ln \left[g(\alpha) / T^{2}\right]=\ln (Z R / \beta E)-E / R T .
$$

A plot of $\ln \left[g(\alpha) / T^{2}\right]$ vs $1 / T$ yields a straight line whose intercept and slope give $\ln (Z R / \beta E)$ and $-E / R$, respectively (Gadalla 1985 ).

Computation of fractional extent parameter ' $\alpha$ ' is explained with the help of a theoretical evolved gas profile as shown in figure 2 (Kamruddin et al 1997). The fractional extent of reaction ' $\alpha$ ' can be defined as

$$
\alpha(T)=Q_{(T)} / Q_{(\text {TOTAL })}=A_{(T)} / A_{(\text {TOTAL })},
$$

where $\alpha(T)$ is the fractional reaction up to temperature $T, Q_{(T)}, A_{(T)}$, extent of gas released and peak area covered till temperature $T$, respectively and $Q_{\text {(TOTAL) }}, A_{\text {(TOTAL) }}$ the total gas release and total peak area respectively. 

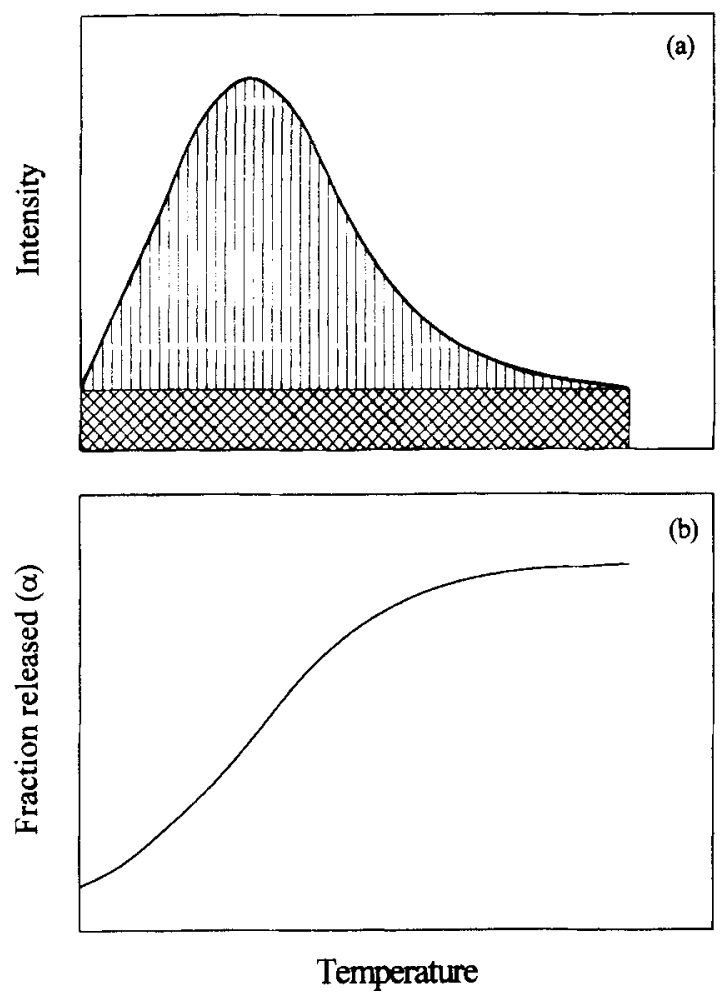

Figure 2. Peak area evaluation procedure.

The area under the peak $A_{\text {(TOTAL) }}$ is determined by summing up the partial pressure/intensity (vertical lines in figure 2) measured at regular and short time intervals (typically 2 to $6 \mathrm{sec}$ ) and subtracting a straight line background (double hatched area in figure 2). For fractional area determination, the same procedure is repeated to find the area subtended by the curve up to any given time/temperature $A_{(T)}$, which is divided by $A_{\text {(TOTAL). }}$.

In our experiments the measured $\alpha(T)$ values corresponding to each release stage were utilized to derive integral model functions of non-isothermal solid state kinetic rate expressions. The experimental $\ln \left\{g(\alpha) / T^{2}\right\}$ vs $1 / T$ plot for each release stage was matched with least square fitted rate expressions. Kinetic control mechanism governing a particular release stage is obtained from the best fit as revealed by the highest correlation coefficient.

\section{Results and discussion}

\section{$4.1 \mathrm{CuSO}_{4} \cdot 5 \mathrm{H}_{2} \mathrm{O}$}

Temperature programmed decomposition of $\mathrm{CuSO}_{4} \cdot 5 \mathrm{H}_{2} \mathrm{O}$ was conducted in the temperature range $300 \mathrm{~K}-1100 \mathrm{~K}$ at heating rates of $3 \mathrm{~K} / \mathrm{min}-14 \mathrm{~K} / \mathrm{min}$. The typical EGA spectra for $100 \mathrm{mg}$ of sample subjected to a heating rate of $3 \mathrm{~K} / \mathrm{min}$ is shown in 

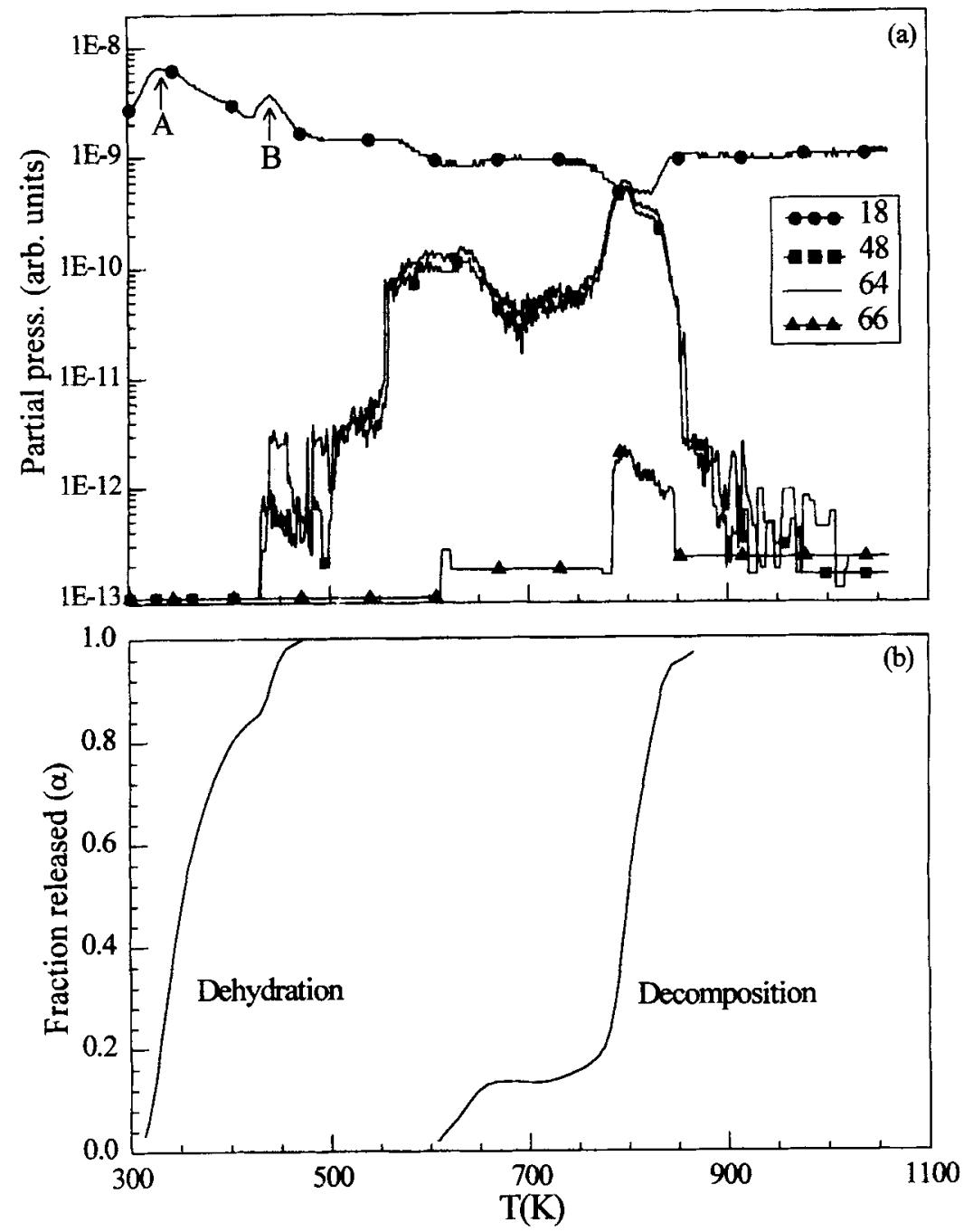

Figure 3. Typical (a) EGA-MS plot and (b) the corresponding fractional release plot for dehydration and decomposition stages of $\mathrm{CuSO}_{4} \cdot 5 \mathrm{H}_{2} \mathrm{O}$.

figure 3a. Dehydration and decomposition steps are clearly separated and it can be seen that the dehydration of the sample occurs in the temperature range of $300 \mathrm{~K}-500 \mathrm{~K}$ (El-Houte et al 1989). This is followed by decomposition which is completed at $900 \mathrm{~K}$. The fraction release plot is shown in figure $3 \mathrm{~b}$. The bimodal dehydration profile signifies a two-stage water release. This release behaviour and the area under the peak $B$ which is one fourth of peak $A$ in figure $3 a$ can be explained on the basis of the reaction,

$$
\mathrm{CuSO}_{4} \cdot 5 \mathrm{H}_{2} \mathrm{O} \rightarrow \mathrm{CuSO}_{4} \cdot \mathrm{H}_{2} \mathrm{O} \rightarrow \mathrm{CuSO}_{4} .
$$

This two-stage water release can be correlated to two distinctly different crystallographic locations of water molecules (Wells 1990). The hydrogen bonded triclinic structure of $\mathrm{CuSO}_{4} \cdot 5 \mathrm{H}_{2} \mathrm{O}$ contains octahedrally coordinated $\mathrm{Cu}^{2+}$ ion and 


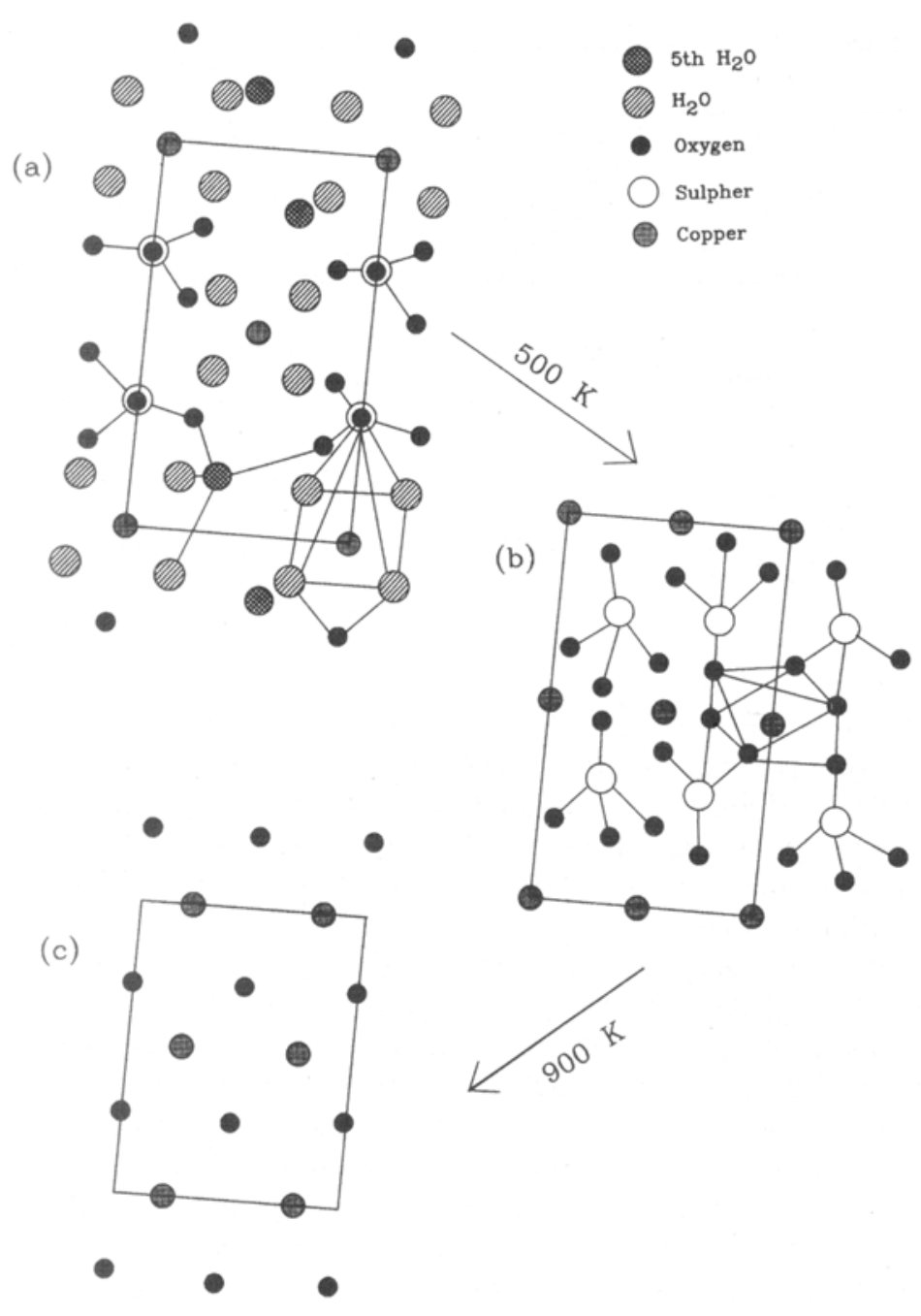

Figure 4. Structural evolution in $\mathrm{CuSO}_{4} \cdot 5 \mathrm{H}_{2} \mathrm{O}$ decomposition: (a) triclinic $\mathrm{CuSO}_{4} \cdot 5 \mathrm{H}_{2} \mathrm{O}$, (b) orthorhombic lattice of anhydrous $\mathrm{CuSO}_{4}$ and (c) monoclinic structure of copper oxide with square planar coordination of $\mathrm{Cu}$ atom.

tetrahedrally coordinated sulphate oxoanion substructure arranged into a cuboidal super structure (Wyckoff 1965). A conceptual view of this structure is shown in figure $4 \mathrm{a}$. The four water molecules and two trans sulphato oxygen atoms form the coordination group around the cation. The fifth water molecule performs a space filling role. It links two independent octahedral and tetrahedral groups by hydrogen bonding. Thus this lone water molecule held between water molecules attached to cation and oxygen atoms of sulphato ion has extra stability and desorbs at higher temperature (Wells 1990). This observation of bimodal water release by EGA is in accordance with the reported neutron diffraction studies on $\mathrm{CuSO}_{4} \cdot 5 \mathrm{H}_{2} \mathrm{O}$ (Mak and Zhou 1992).

The kinetic analysis (table 2) revealed the best fit for the dehydration (correlation coefficient 0.999) as the reaction mechanism based on Mampel unimolecular law 
Table 2. Activation energy and frequency factors for dehydration and decomposition of $\mathrm{CuSO}_{4} \cdot 5 \mathrm{H}_{2} \mathrm{O}$.

\begin{tabular}{|c|c|c|c|c|c|}
\hline & \multicolumn{2}{|c|}{ Dehydration } & \multicolumn{3}{|c|}{ Decomposition } \\
\hline & \multirow{2}{*}{$\begin{array}{c}\text { Random } \\
\text { nucleation }\end{array}$} & \multirow{2}{*}{$\begin{array}{l}3 \mathrm{D} \text { Phase } \\
\text { boundary } \\
\text { migration }\end{array}$} & \multicolumn{2}{|c|}{ 3D Diffusion } & \multirow{2}{*}{$\begin{array}{l}\text { 3D Phase } \\
\text { boundary } \\
\text { migration }\end{array}$} \\
\hline & & & Jander & Brounshtein & \\
\hline $\begin{array}{l}\text { Activation } \\
\text { energy } \\
(\mathrm{kJ} / \mathrm{mol})\end{array}$ & 20.864 & 21.764 & $220 \cdot 253$ & $198 \cdot 253$ & $107 \cdot 367$ \\
\hline $\begin{array}{l}\text { Frequency } \\
\text { factor } \\
\left(\mathrm{sec}^{-1}\right)\end{array}$ & 0.781 & 094 & $1.4 \times 10^{10}$ & $4.8 \times 10^{8}$ & $3.1 \times 10^{5}$ \\
\hline $\begin{array}{l}\text { Correlation } \\
\text { coefficient }\end{array}$ & 0.999 & 0.997 & 0.999 & 0.998 & 0.997 \\
\hline
\end{tabular}

formulated through random nucleation approach. In this approach, two dimensional growth of randomly placed product nuclei in the form of edge shaped planar circular discs proceeds simultaneously with uncovering of surface water by desorption. This approach for explaining dehydration of $\mathrm{CuSO}_{4} \cdot 5 \mathrm{H}_{2} \mathrm{O}$ has also been reported from $\mathrm{X}$-ray diffraction studies (Zagray et al 1979). Our EGA results on dehydration are in agreement with this model.

The decomposition of $\mathrm{CuSO}_{4}$ yields $\mathrm{CuO}$ and $\mathrm{SO}_{3}$, with $\mathrm{SO}_{3}$ further decomposing to $\mathrm{SO}_{2}$ and $\frac{1}{2} \mathrm{O}_{2}$ (Leskela et al 1993). The decomposition product $\mathrm{SO}_{3}$ is not detected by mass spectrometer in our experiments perhaps due to its instability in oxygen deficient high temperature environment, which is in agreement with the earlier work (Brown et al 1980). The ion $\mathrm{SO}_{2}^{+}$along with its fragments formed by electron impact ionization in the ion source of the quadrupole mass spectrometer was detected. The ions $\mathrm{O}^{+}, \mathrm{SO}^{+}$ and $\mathrm{SO}_{2}^{+}$were observed and their intensity variation is sketched in the EGA spectra shown in figure 3. The oxide of higher isotope of sulphur ${ }^{34} \mathrm{SO}_{2}$ has also been detected. The ratio of peak areas inscribed by these two oxides corresponds to the natural abundance ratio i.e. $4 \%$.

The best correlation for decomposition mechanism (correlation coefficient 0.999) was found with the rate expression propounded by Jander, on the basis of three dimensional diffusion. This is followed by Ginstling-Brounshtein mechanism, which shows a correlation coefficient 0.998. Like Jander's approach, the later mechanism is also based on three dimensional diffusion. However, here due allowance is made for differences in reactant and product molar volumes. The compliance of diffusion controlled mechanism can be attributed to the formation of product barrier layer which has to be permeated by the gases for the reaction to proceed.

Both dehydration as well as decomposition steps also show agreements with the kinetic expressions formulated for three dimensional geometric phase boundary interface migration. The appearance of a phase boundary can be attributed to the structural transformations accompanying temperature programme. Upon dehydration the triclinic $\mathrm{CuSO}_{4} \cdot 5 \mathrm{H}_{2} \mathrm{O}$ structure converts to orthorhombic anhydrous $\mathrm{CuSO}_{4}$ (Wyckoff 1965) consisting of $\mathrm{Cu}$ atoms surrounded by distorted octahedron of oxygen 


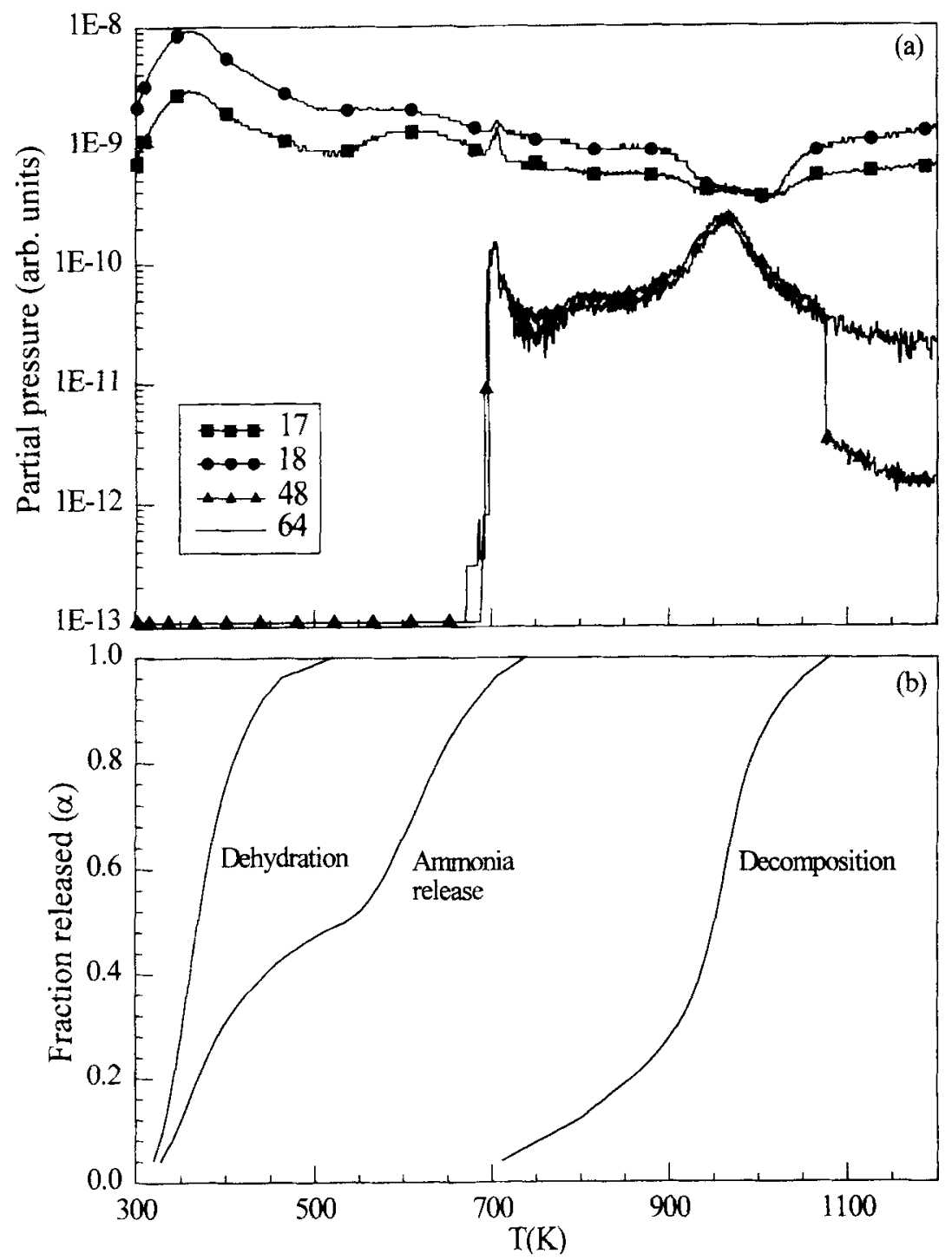

Figure 5. Typical (a) EGA-MS plot and (b) the corresponding fractional release plot for dehydration, ammonia release and decomposition stages of $\mathrm{AlNH}_{4}\left(\mathrm{SO}_{4}\right)_{2} \cdot 12 \mathrm{H}_{2} \mathrm{O}$.

atoms with sulphato oxyanion tetrahydra, alternatively oriented, filling the space as shown in figure $4 \mathrm{~b}$. A further rise in temperature programme leads to disruption of sulphate groups yielding $\mathrm{SO}_{3}$ gas. The structure transforms to monoclinic $\mathrm{CuO}$ having a square planar oxygen coordination for Cu atoms (Wyckoff 1965). A projection of this structure is given in figure $4 \mathrm{c}$. Figure 4 gives the overall schematic of various structural transformations occurring along the temperature programmed decomposition of $\mathrm{CuSO}_{4} \cdot 5 \mathrm{H}_{2} \mathrm{O}$. For this interface transformation, the EGA data yields a correlation coefficient 0.997 for both stages. The activation energy and frequency factors derived for various reaction stages are given in table 2 . 
Figure 5a shows the EGA-MS plot of $\mathrm{AlNH}_{4}\left(\mathrm{SO}_{4}\right)_{2} \cdot 12 \mathrm{H}_{2} \mathrm{O}$ at a heating rate of $6 \mathrm{~K} / \mathrm{min}$ in the temperature range of $300-1200 \mathrm{~K}$. The corresponding fractional release plot is shown in figure $5 \mathrm{~b}$. The dehydration of the sample under vacuum takes place in the temperature range $300-500 \mathrm{~K}$. Ammonia release occurs in three stages. The first stage of ammonia release is concomitant with dehydration whereas the stage II occurs in the temperature range $530-690 \mathrm{~K}$. In our TG/DTA experimental runs, the dehydration step and the first stage of $\mathrm{NH}_{3}$ release were not separated out and a single net weight loss was observed. The stage III refers to a minor release peak around $700 \mathrm{~K}$ which signals the onset of decomposition of aluminium sulphate.

The decomposition of alum yields $\gamma-\mathrm{Al}_{2} \mathrm{O}_{3}$ and $\mathrm{SO}_{3}$, with $\mathrm{SO}_{3}$ further decomposing to $\mathrm{SO}_{2}$ and $\frac{1}{2} \mathrm{O}_{2}$ due to reasons mentioned earlier. The decomposition occurs by evolution of one mole of $\mathrm{SO}_{3}$ at $710 \mathrm{~K}$, another mole at $800 \mathrm{~K}$ and the remaining two moles at $950 \mathrm{~K}$. This decomposition sequence is in agreement with the reported thermogravimetric data on alum (Pizzolato and Papazian 1970).

The best correlation for dehydration at lower heating rates was found with Mampel unimolecular law formulated through random nucleation approach. A change in this rate governing mechanism was observed at higher heating rates. At higher heating rates, the diffusion limitations predominate over random nucleation. Better correlations were observed with $3 \mathrm{D}$ diffusion models. This can be attributed to thermal gradient driven mass transfer effects caused by higher heating rates.

The multiple ammonia release stages indicate varying degree of thermal stability associated with non-equivalent crystallographic locations of ammonium ions in the basic alum structure. The stage I ammonia release data shows consistent correlations with three dimensional diffusion approach based on Jander formalism. The reason can be ascribed to progressive build-up of barrier layer of intermediate products which needs to be permeated for gas release. The higher $E$ value at $14 \mathrm{~K} / \mathrm{min}$ (table 3 ) is perhaps due to larger overlap of stage II release which was not resolved completely. The stage II ammonia release shows compliance with Brounshtein mechanism propounded on the basis of three dimensional diffusion. As substantial volume changes occur during stage II ammonia release leading to formation of $\mathrm{Al}_{2}\left(\mathrm{SO}_{4}\right)_{3}$, this mechanism prevails. As stage III is contributed by a burst of residual ammonia in short temperature range, separate kinetics could not be evaluated.

The final stage of decomposition which leads to the formation of $\gamma-\mathrm{Al}_{2} \mathrm{O}_{3}$, is again governed by random nucleation, a process closely controlled by surface desorption of gases from finely dispersed crystallites. This happens due to band disruption process leading to appearance of nascent surfaces acting as nucleation sites. Table 3 summarizes the correlation coefficients, operating mechanisms, activation energies and preexponential factors corresponding to various decomposition stages. These activation energies match well with the values reported by Johnson et al (1971) in their isothermal experiments.

$\mathrm{X}$-ray powder diffraction studies were carried out on initial alum sample as well as on left over residue material after each decomposition regime in an attempt to identify the intermediate products and propose a reaction scheme. The XRD patterns are shown in figure 6 and various structural phases are depicted in figure 7. It is seen that the extensively hydrogen bonded pristine alum having alunite structure (Mak and Zhou 1992) containing six coordinated regular $\mathrm{Al}\left(\mathrm{H}_{2} \mathrm{O}\right)_{6}$ octahedra and twelve coordinated 
Table 3. Reaction mechanism, corresponding correlation coefficients, activation energy and pre-exponential factors for various stages of decomposition of $\mathrm{AlNH}_{4}\left(\mathrm{SO}_{4}\right)_{2} \cdot 12 \mathrm{H}_{2} \mathrm{O}$ at different heating rates.

\begin{tabular}{|c|c|c|c|c|}
\hline $\begin{array}{l}\text { Heating rate } \\
(\mathrm{K} / \mathrm{min})\end{array}$ & Mechanism & $\begin{array}{l}\text { Correlation } \\
\text { coefficient }\end{array}$ & $\begin{array}{l}\text { Activation energy } \\
(\mathrm{kJ} / \mathrm{mol})\end{array}$ & $\begin{array}{l}\text { Pre-exponential } \\
\text { factors }\left(\mathrm{sec}^{-1}\right)\end{array}$ \\
\hline \multicolumn{5}{|l|}{ Dehydration } \\
\hline 3 & Al & 0.986 & $29 \cdot 27$ & $18 \cdot 3$ \\
\hline 6 & A1 & 0.983 & $27 \cdot 3$ & 8.7 \\
\hline 10 & D3 & 0.976 & $37 \cdot 6$ & $29 \cdot 6$ \\
\hline 14 & D3 & 0.969 & 42.09 & $18 \cdot 8$ \\
\hline \multicolumn{5}{|c|}{$\mathrm{NH}_{3}$ release : stage I } \\
\hline 3 & D3 & 0.986 & $45 \cdot 52$ & $1.2 \times 10^{2}$ \\
\hline 6 & D3 & 0.96 & $17 \cdot 36$ & $4.0 \times 10^{-3}$ \\
\hline 10 & D3 & 0.95 & $28 \cdot 32$ & $0 \cdot 1$ \\
\hline 14 & D3 & 0.99 & $47 \cdot 27$ & 66.5 \\
\hline \multicolumn{5}{|c|}{$\mathrm{NH}_{3}$ release : stage $\mathrm{II}$} \\
\hline 3 & $\mathrm{D} 2$ & 0.996 & $16 \cdot 1$ & $2.6 \times 10^{-3}$ \\
\hline 3 & $\mathrm{D} 4$ & 0.995 & $18 \cdot 4$ & $1.8 \times 10^{-3}$ \\
\hline 6 & $\mathrm{D} 2$ & 0.996 & $25 \cdot 5$ & $4.3 \times 10^{-2}$ \\
\hline 6 & $\mathrm{D} 4$ & 0.998 & $30 \cdot 46$ & $5.1 \times 10^{-2}$ \\
\hline 10 & $\mathrm{D} 2$ & 0.992 & 32.00 & $0 \cdot 26$ \\
\hline 10 & D4 & 0.993 & $35 \cdot 27$ & $2 \cdot 1$ \\
\hline \multicolumn{5}{|l|}{ Decomposition } \\
\hline 3 & Al & 0.986 & 269.95 & $1.5 \times 10^{12}$ \\
\hline 6 & $\mathrm{~A} 1$ & 0.97 & $321 \cdot 58$ & $1.7 \times 10^{14}$ \\
\hline 10 & Al & 0.986 & $323 \cdot 84$ & $4.7 \times 10^{14}$ \\
\hline 14 & Al & 0.98 & $187 \cdot 0$ & $5.1 \times 10^{6}$ \\
\hline
\end{tabular}

monovalent $\mathrm{NH}_{4}\left[\left(\mathrm{H}_{2} \mathrm{O}\right)_{6} \mathrm{O}_{6} *\right]$ distorted octahedra packed into a cubic superstructure (Larson and Cromer 1967). O* refers to oxygen from sulphato groups. The sulphato tetrahedra lies on a three fold axis of the cubic unit cell and is oriented with three oxygen atoms coordinated to monovalent cation. The water molecules occur in crown configuration. Figure 7 a provides a perspective schematic depicting the locations of various substructural units in $\alpha$-alum. The corresponding powder X-ray diffractogram is given in figure $6 \mathrm{a}$ which shows multiple reflection lines. However, the XRD pattern acquired after dehydration and stage I ammonia release, given in figure $6 \mathrm{~b}$, shows total collapse of crystal structure probably due to disappearance of hydrogen bonding. The simultaneous water and ammonia release in stage I arises due to disruption of water coordination sphere of monovalent cation. At temperatures beyond $500 \mathrm{~K}$, formation of recrystallized intermediate results in numerous Bragg diffraction lines as shown in figure $6 \mathrm{c}$. This structure is partially ammoniated. Here the ammonia is bound to oxygen atoms of sulphato ligands. The second and third ammonia release between temperature 500 and $700 \mathrm{~K}$ results in the formation of anhydrous aluminium sulphate which has $\mathrm{Al}_{13} \mathrm{O}_{40}$ groups consisting of six $\mathrm{AlO}_{6}$ octahedra bound together by sharing edges and enclosing an $\mathrm{AlO}_{4}$ tetrahedra at the centre. Sulphato groups occupy the space between the $\mathrm{Al}_{13} \mathrm{O}_{40}$ groups (Wyckoff 1965). 

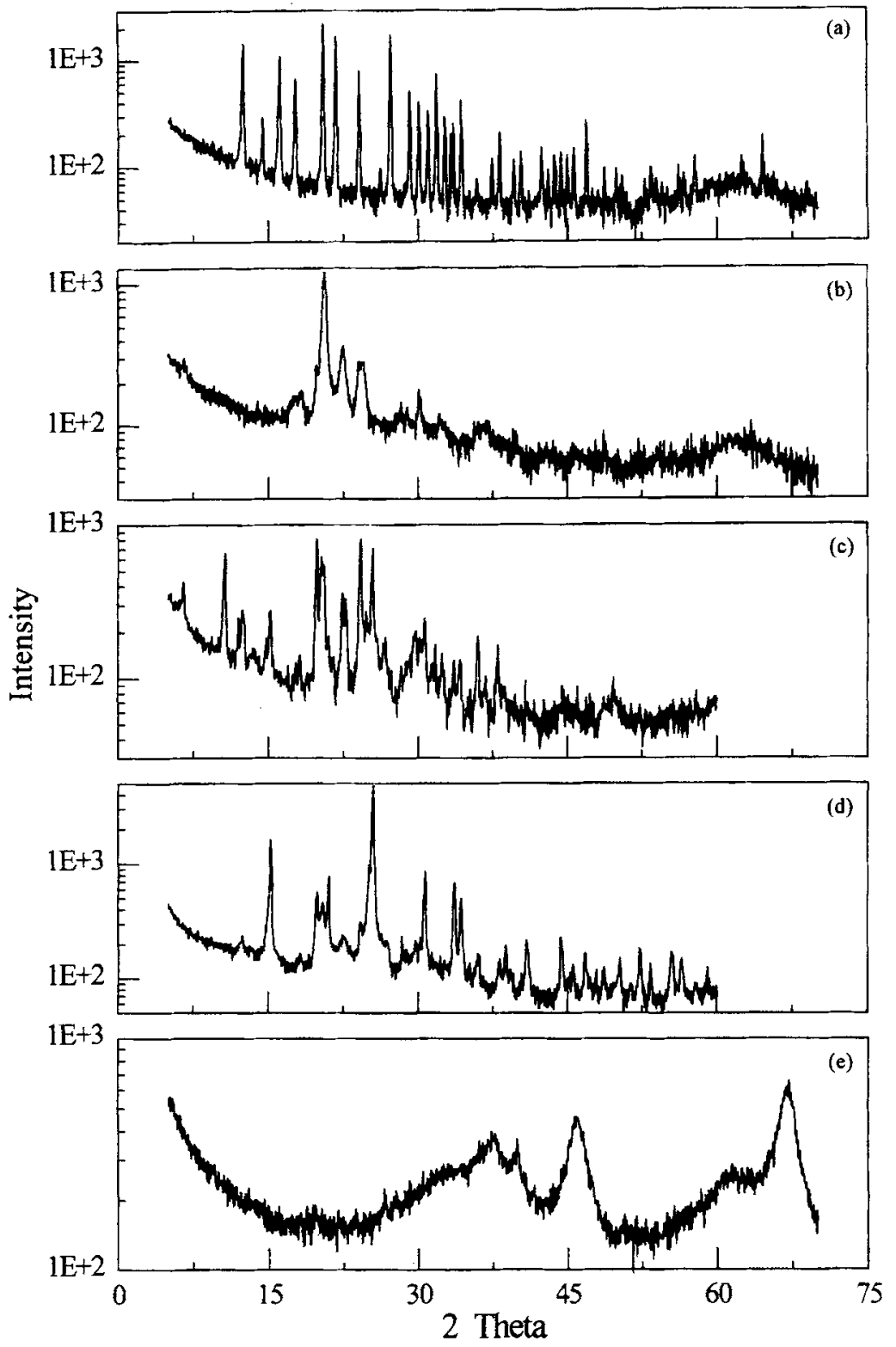

Figure 6. X-ray diffractogram of (a) original alum sample, (b) amorphized sample after dehydration and stage I ammonia release, (c) recrystallized intermediate, (d) deammoniated aluminium sulphate structure preceding to formation of $\gamma-\mathrm{Al}_{2} \mathrm{O}_{3}$ and (e) final product $\gamma-\mathrm{Al}_{2} \mathrm{O}_{3}$.

A conceptual schematic is shown in figure $7 \mathrm{~b}$. The reflection lines of diffractogram shown in figure $6 \mathrm{~d}$ probably corresponds to the crystallites of de-ammoniated aluminium sulphate. Further increase in temperature programme beyond $700 \mathrm{~K}$ results in cleavage of sulphato ligands leading to release of $\mathrm{SO}_{3}$ gas. Upon completion of $\mathrm{SO}_{3}$ release at around $1100 \mathrm{~K}$, the structural reorganization among various $\mathrm{Al}-\mathrm{O}$ units result in the formation of $\gamma-\mathrm{Al}_{2} \mathrm{O}_{3}$. This is a defect spinel structure in which not all 


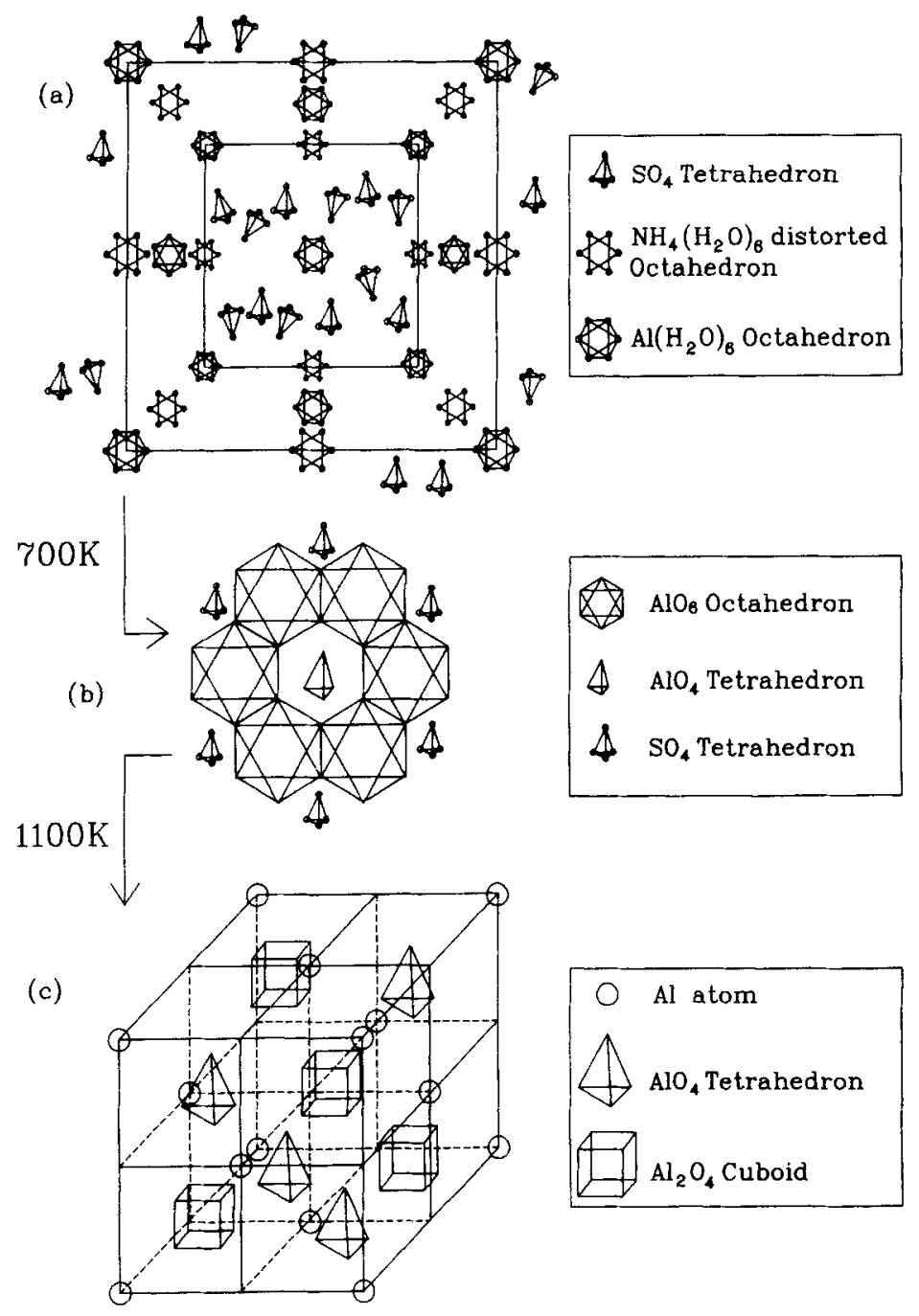

Figure 7. Structural evolution in $\mathrm{AlNH}_{4}\left(\mathrm{SO}_{4}\right)_{2} \cdot 12 \mathrm{H}_{2} \mathrm{O}$ decomposition: (a) perspective view of $\alpha$-alum, (b) conceptual schematic of $\mathrm{Al}_{2} \mathrm{SO}_{4}$ and (c) defect spinel structure of $\gamma-\mathrm{Al}_{2} \mathrm{O}_{3}$.

cation sites are occupied (Ed. Bruce King 1994). It can be written as $\mathrm{Al}_{64 / 3} \square_{8 / 3} \mathrm{O}_{32}$. The structure is face centred cubic with respect to $\mathrm{Al}$ and its alternate octants are occupied by either $\mathrm{Al}_{2} \mathrm{O}_{4}$ cuboid or $\mathrm{AlO}_{4}$ tetrahedron as shown in figure 7c. The XRD pattern of final residue, shown in figure $6 \mathrm{e}$, corresponds to $\gamma-\mathrm{Al}_{2} \mathrm{O}_{3}$ structure.

\section{Conclusion}

In summary, we have described the EGA-MS facility custom built by us in our laboratory and presented results pertaining to temperature programmed decomposition of $\mathrm{CuSO}_{4} \cdot 5 \mathrm{H}_{2} \mathrm{O}$ and $\mathrm{AlNH}_{4}\left(\mathrm{SO}_{4}\right)_{2} \cdot 12 \mathrm{H}_{2} \mathrm{O}$. Various kinetic control regimes associated with different reaction stages could be established. It is seen that the initial 
release of surface water is mostly governed by nucleation and growth mechanism. Intermediate decomposition stages were found to be diffusion controlled due to product barrier layer resistance. But in case of formation of new structure phases, kinetics based on phase boundary control seem to be prevalent. The kinetics leading to end product formation sometimes exhibit reversal to nucleation and growth formalism. The reason can be attributed to generation of nascent nucleation sites through formation of active surfaces caused by bond disruptive effects. Also EGA-MS data as well as structural transformation in the condensed phase are found to be mutually supportive.

\section{Acknowledgement}

The authors thank Shri P K Ajikumar, Shri R Krishnan, Dr K Govindarajan, Dr B Purniah, Shri J Jayapandian, Shri G V N Rao, Shri V S Sastry and Dr J Janaki for their help during the course of this work. We also express our sincere gratitude to Dr T S Radhakrishnan, Dr K Krishan, Dr Baldev Raj and Dr P Rodriguez for their support and encouragement.

\section{References}

Agrawal R K 1992 Thermochim. Acta 20393

Ajikumar P K, Kamruddin M, Dash S and Tyagi A K 1996 Proc. of seventh national symp. on mass spectrometry (Gwalior: Indian Society for Mass Spectrometry) p. 493

Barnes P A 1987 Thermochim. Acta 1141

Barnes P A, Parkes G M B and Charsley E L 1994 Anal. Chem. 662226

Bell A T, Manzer L E, Chen N Y, Weekman V W, Hegedus L L and Periera C J 1995 Chemical Engineering Progress

Benham M J and Ross D K 1989 Z. Phys. Chem. Neue Folge 16325

Brown M E, Dollimore D and Galwey A K 1980 Comprehensive chemical kinetics, in Reactions in the solid state, (eds) C H Bamford and C F H Tipper (Amsterdam: Elsevier) Vol. 22, Chapter 3

Brown M E 1988 Introduction to thermai analysis (London: Chapman and Hall) Chapter 13

Ed. Bruce King R 1994 Encyclopedia of inorganic chemistry (Chichester: John Wiley and Sons) Vol. 1, part III, p. 111

Dash S, Kamruddin M, Ajikumar P K, Tyagi A K and Krishan K 1995 Bull. Indian Vac. Soc. 2631

Dash S, Krishnan R, Kamruddin M and Tyagi A K 1997 Indian J. Chem. (in press)

Davis M E 1991 Ind. Eny. Chem. Res. 301675

Dollimore D 1992 Thermochim. Acta 2037

Dossi C, Fusi A and Psaro R 1994 Thermochim. Acta 164173

El-Houte S, El-Sayed Ali and Toft Sovenson O 1989 Thermochim. Acta 138107

Eroglu M S and Guven O 1996 J. Appl. Polym. Sci. 61201

Flynn J H 1988 J. Thermal Anal. 34367

Gadalla A M 1985 Thermochim. Acta 95179

Gallagher P K 1982 J. Thermal Anal. 257

Gordiets B, Ferreira C M, Nahorny J, Pagnon D, Touzeau M and Vialle M 1996 J. Phys. D: Appl. Phys. 29 1021

Jaenicke-Rößler K, Leitner G and Muller F 1994 Fresenius J. Anal. Chem. 349170

Jisheng Wang and Brian McEnaney 1991 Thermochim. Acta 190143

Johnson Jr D W and Gallagher P K 1971 J. Am. Ceram. Soc. 54461

Kaisersberger E 1979 Thermochim. Acta 29215

Kamruddin M, Ajikumar P K, Dash S, Purniah B, Tyagi A K and Krishan K 1995 Instrum. Sci.\& Technol. 23123

Kamruddin M, Ajikumar P K, Dash S, Krishnan R, Tyagi A K and Krishan K 1997 J. Thermal Anal. 48277 
Koga N, Malek J, Sestak J and Tanaka H 1993 Netsu Sokutei 20210

Langer H G 1983 Evolved gas analysis in treatise' on analytical chemistry led.) E J Elving (New York: John Wiley and Sons) 2nd Edition Part 1. Vol. 12. chapter 6

Larson A C and Cromer D T 1967 Acta Crystallogr. 22793

Leskela T, Lippmaa M. Niinisto L and Soininen P 1993 Thermochim. Acta 2149

Lorinci G, Matuschek G. Fekete J, Gebclugi I and Kettrup A 1995 Thermochim. Aita 26373

Mak T C W and Gong-Du Zhou 1992 Crystallography in modern chemistry (New York: Wiley and Sons Inc.) pp 135,277

Mullens J, Carleer R. Reggers G. Ypeiman J, Vanhees J and Van Poucke L C 1992 Thermochim. Acta 212219 Pizzolato P J and Papazian H A 1970 J. Am. Ceram. Soc. 53289

Price D, Dollimore D, Fatemi N S and Whitehead R 1980 Thermochim. Acta 42323

Price D, Fatemi N S, Dollimore D and Whitehead R 1985 Thermochim. Acia 94313

Pysiak J and Pacewska B 1980 J. Thermal Anal. 1979

Saraswathy N 1994 Control and data acquisition of quadrupole mass analysers. Project report. University of Madras

Sestak J, Satava V and Wendlandt W W 1973 Thermochim. Acta 7332

Stucker T 1991 Chemical Engineering

Szekely J, Evans J W and Sohn H Y 1976 Gas solid reactions (New York: Academic Press)

Wells A F 1990 Structural inorganic chemistry (Oxford: Clarendon Press) 5th edition p. 678

Wyckoff R W G 1965 Crystal structures (New York: Interscience Publishers) 2nd edition pp 764, 40, 140,895

Zagray A l, Zyryanor V V, Lyakhov N Z, Chupakhin A P and Boldyrev V V 1979 Thermochim. Acta 29115 